\title{
Percent Predicted Functional Residual Capacity
}

National Cancer Institute

\section{Source}

National Cancer Institute. Percent Predicted Functional Residual Capacity. NCI Thesaurus.

Code C126052.

The volume of air remaining in the lungs after a normal exhalation as a proportion of the predicted normal value. (CDISC) 